tricks, such as the learned pig, which could spell out words. They also displayed unfortunate humans, such as microcephalics and hairy women, who were branded as 'freaks' for showing animal characteristics.

The boundaries came close to merging in the nineteenth century. The widespread study of primate anatomy and behaviour made the similarities between humans and apes hard to dismiss. Satirists saw this as an opportunity: for example, one hairy creation, Sir Oran Haut-Ton, bought a baronetcy and entered parliament - where, his creator reported, little distinguished his behaviour from that of his fellows aside from his muteness. Darwin's influence on our mental image of primitive man is unmistakable. In Renaissance pictures, he is clearly Homo sapiens, albeit extremely unkempt. PostDarwin paintings endow primitive man with decidedly simian characteristics.

Kemp's book is beautifully illustrated and written, but the breadth of its discussion is packed into a form that may be too abbreviated. It is not a light read, and sometimes one struggles to follow the thread of the narrative. Then again, it is not supposed to be a linear plot. How else could all this knowledge be shoe-horned into a coffee-table format?

Also packed in are discussions of the science of phrenology, as developed by Franz Joseph Gall in the first half of the nineteenth century, and the fashion for quantification of primitiveness through measurement of jaw angle - the ideal reference being Apollo Belvedere (who was decidedly caucasian) from antiquity.

The great French nineteenth-century neuroscientist Paul Broca also made the error of assuming that caucasians must provide the baseline. However, he was forced to abandon his theory that intelligence was related to brain size when facts intervened - his own measurements showed that the brains of some non-caucasian races were in fact larger. His contemporary Cesare Lombroso, who launched the field of criminal anthropology, even tried to match skulls with particular shapes, and brains with particular features, to show that those with criminal tendencies had the physical attributes of the throwback - or of other animals such as apes, or even rats.

With hindsight, it is easy to scoff at these past theories. Instead, Kemp acknowledges most of them as appropriately reflecting the state of knowledge at the time. Gall's phrenology, he notes, had its own internal logic and was based on careful, systematic measurements.

Robert Louis Stevenson was also of his scientific time. His Mr Hyde is a Lombroso-style atavistic regression, exemplifying the thin veneer of civilization that only just manages to repress our natural animalistic tendencies. Dr Jekyll's dilemma resonates as strongly in today's sophisticated times - the adjective 'Jekyll-andHyde' has made its way into the Oxford English Dictionary.

Alison Abbott is Nature's Science in Culture editor and senior European correspondent.

\title{
A question of truth
}

\section{A Certain Ambiguity: A Mathematical Novel \\ by Gaurav Suri and Hartosh Singh Bal \\ Princeton University Press: 2007. 304 pp. \\ £16.95, \$27.95}

\section{Katherine Körner}

When Euclid laid out his axioms of geometry - five statements on the properties of points, lines, circles and angles that he believed to be self-evident - he sought to demonstrate further truths by building logically on these supposedly indisputable foundations. A Certain Ambiguity uses the structure of a novel to explore the nature of the beauty inherent in such mathematical arguments, and of the truth to which they lead.

The authors' commitment to wowing their characters as much as their readers is one of the book's strongest points. Gaurav Suri and Hartosh Singh Bal draw on some of the most elegant results in the ancient Greek arsenal - proofs that there are infinitely many prime numbers, for instance, and that the square root of 2 cannot be written as a fraction. The book's characters and readers are led through deep (but accessible) reasoning before being challenged with questions about what makes these arguments valid, and on what this validity depends.

The book is at its most successful, and the story at its most engaging, when the authors allow their natural exuberance to carry them away. The joy that accompanies their early excursions into proof will buoy up a floundering newcomer, while allowing old hands to recall the thrill of meeting the ideas for the first time.

Through a series of court transcripts rationed out over the course of the book, the narrator's grandfather, under arrest for blasphemy in 1919, talks his judge, his grandson and us through the components of logical argument and his belief in the truth derived from it. Only the judge is allowed to answer back, and the discussions that ensue are by far the most gripping and entertaining aspect of the book. Together, judge and grandfather journey from their delight at finding a way through simple proofs, to awe at the world this reveals, all the way to spiritual torment when the truth of Euclid's axioms is brought into question. In one of the most profound sections, the authors offer a lucid introduction to the rejection of one of these axioms by noneuclidean geometry.

We also follow the less-stimulating conversations of the narrator with his undergraduate friends as they, too, grapple with the nature of truth. Although their mathematical focus on our knowledge of infinity is fascinating and well presented, the discussions themselves are common to those of many students in the pub at closing time and do not particularly enlighten the reader or add much of interest. Each of these characters seems to have had his or her list of personality traits allocated at random, and it was galling to see 'love interest' on the list of the only important female character flagged up from early on.

The book's main weakness is that these same characters are tedious. The grandfather's story

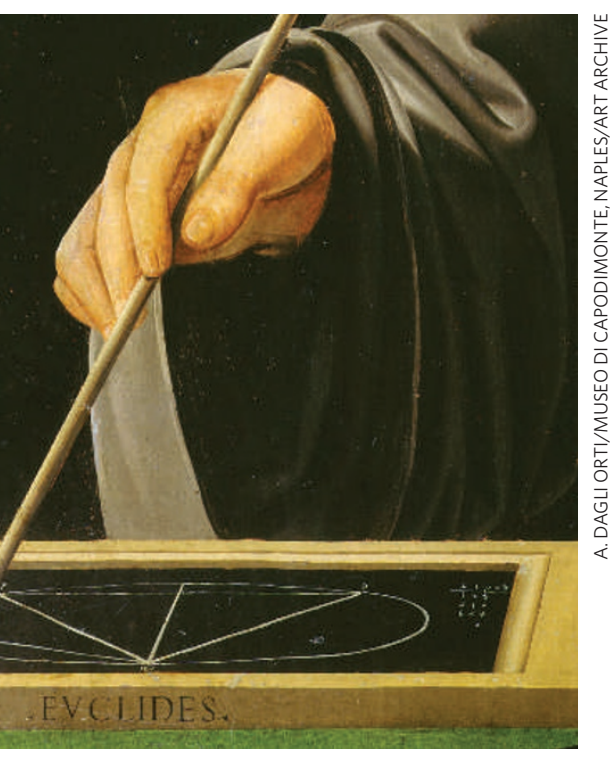

ed to demonstrate other geometric truths.

is compelling, and the combination of socratic dialogue and very human digressions throughout should interest those readers less inclined to mathematical textbooks. But - just as the characters' excitement in mathematics encourages the reader's - when it is hard to warm to the characters, it is hard to care about the topics they choose to discuss.

In any introduction to a subject, there will be areas the specialist might wish to see covered in more depth or from a different angle. The interested layperson, however, should take from A Certain Ambiguity a good grounding and a new curiosity that will help them tackle the books referenced in the bibliography. Mathematicians should enjoy the infectious enthusiasm with which the discipline is presented, and it could even spur them into finding new ways to share their own passion.

Katherine Körner is a graduate student in the Department of Mathematics, Harvard University, $10 x$ ford Street, Cambridge, Massachusetts 02138, USA. 